\title{
THE CORRELATION OF TRANEXAMIC ACID USED AS ANTIFIBRINOLYTIC THERAPY TO GLASGOW COMA SCALE FOR THE FIRST 7 DAYS IN HEMORRHAGIC STROKE PATIENTS
}

\author{
CHRISTIANUS HERU SETIAWAN ${ }^{1 *}$, ZULLIES IKAWATI ${ }^{2}$, ABDUL GOFIR ${ }^{3}$
}

${ }^{1}$ Department of Pharmacology and Clinical Pharmacy, Faculty of Pharmacy, Sanata Dharma University, Indonesia. ${ }^{2}$ Department of Pharmacology and Clinical Pharmacy, Faculty of Pharmacy, Gadjah Mada University, Indonesia. ${ }^{3}$ Department of Neurology, Stroke Unit Dr. Sardjito Hospital, Indonesia. Email: chs_heru@usd.ac.id

Received: 24 November 2016, Revised and Accepted: 24 January 2017

ABSTRACT

Objective: Treatment of hemorrhagic stroke using tranexamic acid is still used in some hospitals, to prevent the occurrence of the complication called rebleeding. Rebleeding is an important cause of bad outcomes that result loss of consciousness and even death. The administration of the antifibrinolytic tranexamic acid in patients with hemorrhagic stroke can reduce the occurrence of rebleeding, but it also can increase poor outcome caused by cerebral ischemia that can worsen the patient's condition.

Methods: This study used observational study design, cohort, prospective, and multicenter. The purpose of this study was to determine the effectiveness of the use of tranexamic acid in patients with hemorrhagic stroke. Statistical testing is done by analyzing the Glasgow coma scale (GCS) score on day $1^{\text {st }}$, day $3^{\text {rd }}$, and day $7^{\text {th }}$ between the treatment groups hemorrhagic stroke patients who received tranexamic acid therapy as antifibrinolytic therapy in Bethesda Hospital for 23 patients compared with a control group of patients hemorrhagic stroke who did not receive therapy as tranexamic acid antifibrinolytic therapy in the Dr. Sardjito Hospital for 23 patients.

Results: The statistical analysis of the independent t-test showed that there was no significant difference between the average GCS score of day $1^{\text {st }}(p=262)$, day $3^{\text {rd }}(p=0.293)$, and day $7^{\text {th }}(p=0.648)$ between treatment group and control group. The statistical analysis of the Mann-Whitney showed that there was not significant difference comparing the difference between the pre and post GCS score at treatment group and control group ( $\mathrm{p}=0.158$ ).

Conclusion: Administration of tranexamic acid in patients with hemorrhagic stroke (treatment group) gives the same clinical response compared to the patients who did not receive tranexamic acid therapy (control group) based on assessment of the GCS score.

Keywords: Hemorrhagic stroke, Tranexamic acid, Glasgow coma scale, Antifibrinolytic.

(c) 2017 The Authors. Published by Innovare Academic Sciences Pvt Ltd. This is an open access article under the CC BY license (http://creativecommons. org/licenses/by/4. 0/) DOI: http://dx.doi.org/10.22159/ajpcr.2017.v10s2.19498

\section{INTRODUCTION}

Stroke is the second leading cause of death in the world in the age group $>60$ years and the fifth leading cause of death in the age group 15-59 years, the prevalence of stroke compared to other causes of death in the world is $10 \%$ or approximately 5.5 million people [1]. Stroke is a syndrome characterized by sudden focal or global functional impairment of the brain that growing very fast lasts more than $24 \mathrm{hrs}$ (unless there is a surgical intervention or lead to death) caused by vascular disorders in the brain [2].

One of the therapy that is commonly used as the treatment of hemorrhagic stroke therapy in the hospital is tranexamic acid, to prevent rebleeding after hemorrhagic stroke. Tranexamic acid is an antifibrinolytic drug given to reduce bleeding, by preventing clot dissolution of blood clots due to bleeding [3]. Causes of poor manifestation of subarachnoid hemorrhage stroke are rebleeding, bleeding occurs from the dissolution of blood clots in blood vessels to rupture. Administration of antifibrinolytics is expected to reduce the risk of the re-bleeding event in hemorrhage stroke patients [4].

According Perdossi (Perhimpunan Dokter Spesialis Saraf Indonesia), giving tranexamic acid is recommended in patients with subarachnoid hemorrhage stroke to prevent rebleeding as antifibrinolytic therapy [5]. Intracerebral hemorrhage stroke patients are not recommended to be given tranexamic acid, intracerebral hemorrhage stroke patients is recommended to be given vitamin $\mathrm{K}$, and fresh-frozen plasma for the treatment of hemolytic, but lately, prothrombin complex concentrates and recombinant factor VIIa have emerged as a potent therapy [6].

Some hospitals still provide tranexamic acid as antifibrinolytic to patients with hemorrhagic strokes either subarachnoid hemorrhage stroke or intracerebral hemorrhage stroke (personal communication, 2013). Thus, it requires further confirmation of the effectiveness of tranexamic acid administration as an antifibrinolytic in patients with hemorrhagic stroke with parameter score on the Glasgow coma scale (GCS).

\section{METHODS}

This study design was observational analytical study in cohort, collected the data prospectively from March 2014 until June 2014 at Bethesda Hospital (treatment group) and the Dr. Sardjito Hospital (control group), and then analyzed how the effects of tranexamic acid as antifibrinolytic use in patients with bleeding strokes against the prognosis of stroke by using the GCS for hospitalized for the first 7 days. The research protocol was approved by the Medical and Health Research Ethics Committee, Faculty of Medicine, Gadjah Mada University by numbers of ethics committee approval KE/FK/456/EC.

\section{Subjects}

Patient diagnosed with hemorrhagic stroke, hospitalized at Bethesda Hospital and the Dr. Sardjito Hospital. The exclusion criteria are patients with impaired blood clotting function, patients who suffered repeated strokes, patients were taken to the hospital $>24$ hrs after the attack, patients were followed up by surgery as a bleeding stroke proceeding, and patients who cannot be judged the initial conditions before getting tranexamic acid therapy, the deadline assessment of initial patients' condition were within $24 \mathrm{hrs}$ after admission to hospital.

\section{Sampling size}

The minimum sample size for evaluating hypertension control within the population received therapy was 22 subjects. The sample 
size was obtained with the formula applied for 2 groups in the population, i.e.

$$
\mathrm{n}=\frac{2 \sigma^{2}\left(\mathrm{Z}_{\alpha / 2}+\mathrm{Z}_{\beta}\right)^{2}}{\mu_{1}-\mu_{2}}
$$

Whereas, $\sigma=$ Standar deviation

$\mathrm{Z}_{\alpha}=0.05$ so $\mathrm{Z}_{\alpha / 2}=1.960$

$\beta=4 \times \alpha=0.2$; If $\beta=0.2$ so $Z_{\beta}=0.842$

$\mu_{1}-\mu_{2}=$ Clinical judgement $=0.5$

\section{Data collection}

The data will be retrieved from the files of patient includes demographic data of patients (age, gender), comorbidities of the patients (diabetes mellitus and dyslipidemia), as well as the entire management of therapy that patients get during hospitalization on diagnosis of hemorrhagic stroke and patient GCS progress.

\section{Data analysis}

Data analysis was carried out in broad outline, namely:

1. The statistical test $t$ unpaired (independent sample t-test) if the data were normally distributed or Mann-Whitney test if data distribution is not normal to compare the score on the GCS between the treatment groups with the tranexamic acid group and without tranexamic acid therapy on day -1 , day 3 , and day 7 .

2. The same test performed to compare the difference in scores GCS day 1 and day 7 of tranexamic acid therapy group (treatment group) receiving no treatment with tranexamic acid group (the control group).

All statistical tests were statistically significant when $\mathrm{p}<0.05$.

\section{RESULTS}

The basic characteristic of the study subjects was obtained through descriptive analysis. A total of 46 patients with hemorrhagic stroke who first diagnosed with hemorrhagic stroke, not getting surgery for the treatment of his/her hemorrhagic stroke, length of hospitalization of at least 7 days, onset of $<24$ hrs, treated with tranexamic acid in Bethesda Hospital (treatment group), and did not get tranexamic acid in Dr. Sardjito Hospital (the control group) as an antifibrinolytic therapy that met inclusion included in the descriptive analysis. Data taken from March 2014 through June 2014 prospectively. Data taken the basic characteristics such as age, sex, and comorbidities (diabetes mellitus and dyslipidemia) are used as baseline data to see the profile of research subjects (Table 1 ).

The basic characteristics such as frequency proportion to age, sex, and comorbidities of diabetes mellitus was no difference between the treatment group and the control group, while the proportion of dyslipidemia comorbidities differ between the treatment group and the control group.

The basic characteristic of which is a risk factor that can influence the outcome score on the GCS are temperature and blood pressure. From the results obtained Mann-Whitney test $p=0.70$, so it can be concluded that there is no average difference between the average temperature of the patient for 7 days in the treatment group and the control group were significant $(\mathrm{p}>0.05$ : There are no significant differences between groups of data that tested). With this test, the temperature data did not differ significantly between the treatment and control groups that did not affect the score on the GCS between the two groups. The test results independent t-test for blood pressure, the results obtained are $p=0.066$ (systole) and $\mathrm{p}=0.468$ (diastole), so it can be concluded that there is no significant difference between average blood pressure systolic and diastolic for 7 days in group control and treatment groups were significant $(\mathrm{p}>0.05)$. Blood pressure did not affect the score on the GCS between the two groups.

Temperature can affect patients prognosis with stroke, high temperatures for $37.5^{\circ} \mathrm{C}$ that occurred during the first $24 \mathrm{hrs}$ was found in $83 \%$ of patients lead to bad outcomes associated with the expansion of ventricular hemorrhage [7].

A decrease in blood pressure in bleeding stroke is to prevent the expansion of bleeding, especially when bleeding from the aneurysm rupture. In primary intracerebral haemorrhage stroke where a specific blood vessel abnormality is not found, the risk of hemorrhage expansion as a smaller rise in blood pressure and should be considered the possibility of cerebral ischemia if there is a decrease in blood pressure [7] (Table 2).

Profile of treatment cannot be analyzed since each patient has a different treatment depending on clinical condition. Furosemide and mannitol therapy cannot be analyzed because there are differences in the treatment group and the control group was due to differences in standard of medical services and clinical condition of the patient (increase in intracranial pressure).

Of all, the data normality test average GCS score in the treatment group and the control group data distribution is not normal, then the

Table 1: The baseline characteristics of hemorrhagic stroke patients in the treatment group, and the control group in March 2014 through June 2014

\begin{tabular}{|c|c|c|c|}
\hline \multirow[t]{2}{*}{ Variable } & \multirow{2}{*}{$\begin{array}{l}\text { Treatment group }(n=23) \\
n(\%)\end{array}$} & \multirow{2}{*}{$\begin{array}{l}\text { Control group }(n=23) \\
n(\%)\end{array}$} & \multirow[t]{2}{*}{ p value } \\
\hline & & & \\
\hline \multicolumn{4}{|l|}{ Age (years) } \\
\hline $61-70$ & $6(26.09)$ & $8(34.78)$ & \\
\hline $51-60$ & $7(30.43)$ & $8(34.78)$ & \\
\hline $40-50$ & $4(17.39)$ & $4(17.39)$ & \\
\hline$<40$ & $1(4.35)$ & $1(4.35)$ & \\
\hline \multicolumn{4}{|l|}{ Sex } \\
\hline Male & $14(60.70)$ & $14(60.70)$ & 0.00 \\
\hline Female & $9(39.30)$ & $9(39.30)$ & \\
\hline \multicolumn{4}{|l|}{ Diabetes melitus } \\
\hline Yes & 11 (47.83) & $10(43.48)$ & 0.048 \\
\hline No & $12(52.17)$ & $13(56.52)$ & 0.04 \\
\hline \multicolumn{4}{|l|}{ Dyslipidemia } \\
\hline Yes & 12 (52.17) & $9(39.13)$ & 0.43 \\
\hline No & 11 (47.83) & $14(60.87)$ & 0.36 \\
\hline Systolic blood pressure an average of 7 days & $142.23 \pm 16.69$ & $152.71 \pm 20.73$ & 0.07 \\
\hline Diastolic blood pressure on average over 7 days & $85.34 \pm 8.67$ & $87.40 \pm 10.31$ & 0.47 \\
\hline
\end{tabular}


Table 2: List of drugs for the treatment of hemorrhagic stroke patients who used the control group and the treatment group during hospitalization 7 days

\begin{tabular}{|c|c|c|c|c|}
\hline No. & Drug classification & Drug & Treatment goup $(n=23)$ & Control group $(n=23)$ \\
\hline \multirow[t]{2}{*}{1.} & Hemostatic & Stoblet $^{\circledR}$ & 8 & 0 \\
\hline & & Vitamin $\mathrm{K}$ & 16 & 0 \\
\hline 2. & Osmotic agent & Manitol & 5 & 21 \\
\hline \multirow[t]{11}{*}{3.} & Antihypertension & Furosemide & 21 & 12 \\
\hline & & $\mathrm{HCT}$ & 0 & 3 \\
\hline & & Bisoprolol & 1 & 1 \\
\hline & & Captopril & 2 & 2 \\
\hline & & Lisinopril & 3 & 0 \\
\hline & & Irbesartan & 3 & 0 \\
\hline & & Candesartan & 1 & 10 \\
\hline & & Valsartan & 0 & 5 \\
\hline & & Nimodipine & 3 & 6 \\
\hline & & Nikardipine & 5 & 5 \\
\hline & & Amlodipine & 13 & 11 \\
\hline \multirow[t]{3}{*}{4.} & Neuroprotective & Piracetam & 5 & 6 \\
\hline & & Citicoline & 7 & 22 \\
\hline & & Mecobalamin & 2 & 4 \\
\hline 5. & Corticosteroid & Dexamethasone & 1 & 2 \\
\hline \multirow[t]{2}{*}{6.} & Antipyretic analgetic & Parasetamol & 5 & 14 \\
\hline & & Ibuprofen & 1 & 0 \\
\hline \multirow[t]{6}{*}{7.} & Antidiabetic & Metformin & 3 & 3 \\
\hline & & Glimepiride & 1 & 0 \\
\hline & & Glikuidon & 1 & 0 \\
\hline & & Acarbose & 1 & 2 \\
\hline & & Pioglitazon & 0 & 3 \\
\hline & & Insulin & 2 & 1 \\
\hline \multirow[t]{3}{*}{8.} & Antihiperlipidemia & Atrovastatin & 3 & 0 \\
\hline & & Simvastatin & 0 & 2 \\
\hline & & Gemfibrozil & 0 & 1 \\
\hline 9. & Antigout & Allopurinol & 1 & 2 \\
\hline
\end{tabular}

HCT: Hydrochlorothiazide

comparison of data between the two hospitals can use statistical test of Mann-Whitney. Table 3 shows the results of statistical analysis using Mann-Whitney, of the test results, showed there was no significant difference between the average score of GCS day 1, day 3 and day 7 in both the treatment group and the control group. From Table 4, it can be seen the difference in score on the GCS day 1 and day 7 between the treatment group and the control group, which is obtained from a reduction in GCS score on day 7 with a GCS score of day 1. From testing normality, the data difference GCS score in the control group was not normal, then tested the Mann-Whitney statistic to compare the difference in score GCS day 1 and day 7 between the treatment group and the control group.

Statistical tests in Table 4 showed no significant difference between comparing the difference in GCS score day 1 and day 7 between the treatment group and the control group, so it can be deduced administration of tranexamic acid in patients with hemorrhagic stroke is not effectively assessed from clinical conditions together with hemorrhage stroke patients who did not receive tranexamic acid therapy based on the difference in score on the GCS between day 1 and day 7 between the treatment group and the control group were consistent with the hypothesis of the study.

\section{DISCUSSION}

From this study showed that administration of tranexamic acid that does not give better improvement for hemorrhage stroke based on GCS score.

In the pilot study by Sprigg et al., administration of tranexamic acid in patients with intracerebral hemorrhage stroke as antifibrinolytic therapy does not provide a significant difference to the placebo group at day 90 based on the Modified Rankin Scale, Barthel Index, and death [8]. Some studies support this result, giving tranexamic acid in patients with subarachnoid hemorrhage stroke as antifibrinolytic
Table 3: Analysis score on the GCS on day 1, day 3, and day 7 between the treatment group and the control group

\begin{tabular}{llll}
\hline Day & $\begin{array}{l}\text { Average GCS score of } \\
\text { treatment groups }\end{array}$ & $\begin{array}{l}\text { Average GCS score of } \\
\text { control group }\end{array}$ & p-value \\
\hline Day 1 & 10.57 & 11.70 & 0.279 \\
Day 3 & 11.48 & 12.43 & 0.295 \\
Day 7 & 12.43 & 11.96 & 0.73 \\
\hline \multicolumn{4}{l}{ GCS: Glasgow coma scale }
\end{tabular}

therapy revealed no significant differences in the parameters of the Glasgow outcome scale (GOS) between tranexamic acid and placebo groups [9-11].

Antifibrinolytic therapy in subarachnoid hemorrhage stroke for 4 weeks after the hemorrhage does not provide better outcomes compared to placebo due to increased ischemic events despite the downturn of rebleeding [12]. According to the Cochrane systematic review of 2008, the use of tranexamic acid as antifibrinolytic therapy in aneurysm subarachnoid hemorrhage stroke patients does not provide clinical improvement, but it can give poor results that are cerebral ischemia [4].

This study, however, still have some limitations. Further, studies are needed for a variety of variables that may influence the clinical score on the GCS in patients with bleeding; such patients receive treatment, initial GCS type of bleeding stroke, hemorrhage volume, site of bleeding, patients received treatment, and the type of treatment the patient received. On the other hand, further research is also needed with a longer period to see the outcome, additional criteria such as motor movements, patient outcomes and scale of the GOS, the incidence of rebleeding and ischemic events at the rupture site.

The use of tranexamic acid as antifibrinolytic therapy in patients with hemorrhagic stroke needs to be reconsidered because of the research 
Table 4: Analysis of differences in score on the GCS on day 1 and day 7 between the treatment group and the control group

\begin{tabular}{|c|c|c|c|c|c|c|c|}
\hline \multirow[t]{2}{*}{ Patient } & \multicolumn{3}{|c|}{ Treatment group } & \multicolumn{3}{|c|}{ Control group } & \multirow[t]{2}{*}{ p value } \\
\hline & Day 1 & Day 7 & GCS difference day 1 and the $7^{\text {th }}$ & Day 1 & Day 7 & GCS difference day 1 and the $7^{\text {th }}$ & \\
\hline Patient 1 & 8 & 8 & 0 & 15 & 15 & 0 & 0.158 \\
\hline Patient 3 & 15 & 15 & 0 & 15 & 15 & 0 & \\
\hline Patient 4 & 14 & 15 & 1 & 15 & 15 & 0 & \\
\hline Patient 5 & 10 & 15 & 5 & 10 & 15 & 5 & \\
\hline Patient 6 & 7 & 15 & 8 & 14 & 9 & -5 & \\
\hline Patient 7 & 6 & 8 & 2 & 12 & 15 & 3 & \\
\hline Patient 8 & 10 & 8 & -2 & 9 & 9 & 0 & \\
\hline Patient 9 & 6 & 15 & 9 & 7 & 4 & -3 & \\
\hline Patient 10 & 10 & 12 & 2 & 13 & 15 & 2 & \\
\hline Patient 11 & 8 & 9 & 1 & 15 & 15 & 0 & \\
\hline Patient 12 & 7 & 10 & 3 & 14 & 9 & -5 & \\
\hline Patient 13 & 9 & 15 & 6 & 15 & 10 & -5 & \\
\hline Patient 14 & 10 & 3 & -7 & 12 & 13 & 1 & \\
\hline Patient 15 & 15 & 15 & 0 & 14 & 15 & 1 & \\
\hline Patient 17 & 14 & 14 & 0 & 15 & 15 & 0 & \\
\hline Patient 18 & 10 & 15 & 5 & 8 & 12 & 4 & \\
\hline Patient 19 & 15 & 15 & 0 & 6 & 10 & 4 & \\
\hline Patient 20 & 15 & 15 & 0 & 9 & 10 & 1 & \\
\hline Patient 21 & 11 & 9 & -2 & 9 & 4 & -5 & \\
\hline Patient 22 & 12 & 15 & 3 & 8 & 9 & 1 & \\
\hline Patient 23 & 10 & 15 & 5 & 4 & 11 & 7 & \\
\hline Average & 10.57 & 12.43 & $1.87 \pm 3.55$ & 11.70 & 11.96 & $0.26 \pm 3.24$ & \\
\hline
\end{tabular}

GCS: Glasgow coma scale

does not provide a better clinical response compared with patients who did not get the bleeding stroke tranexamic acid therapy.

\section{CONCLUSION}

Giving tranexamic acid in patients with hemorrhagic stroke as antifibrinolytic therapy is not effective assessed from similar clinical responses to patients with hemorrhagic stroke who do not get treatment tranexamic acid based on ratings GCS on day 1 , day 3 , and day -7 .

\section{ACKNOWLEDGMENT}

Sincere gratitude to the Head of Bethesda Hospital and Dr. Sardjito Hospital for permission to collect data in the stroke unit at both hospitals, and finally to all of the clinician and nurse for the support during collecting data at both hospitals.

\section{REFERENCES}

1. Goldstein LB, Adams R, Alberts MJ, Appel LJ, Brass LM, Bushnell CD. Primary prevention of ischemic stroke: A guideline. Am Heart Assoc 2006;37:1583-633

2. Gofir A. Manajemen Stroke. $2^{\text {nd }}$ ed. Yogyakarta: Pustaka Cendekia Press; 2011.

3. Allen H. Tranexamic Acid for Bleeding, Medicine. Egton Med Inf Syst Ltd.; 2012. Available from: http://www.patient.co.uk/medicine/ Tranexamic-acid.htm. [Last cited on 2014].

4. Roos YB, Rinkel GJ, Vermeulen M, Algra A, van Gijn J. Antifibrinolytic therapy for aneurysmal subarachnoid haemorrhage. Cochrane Database Syst Rev 2008;2:CD001245.
5. Perhimpunan Dokter Spesialis Saraf Indonesia. Guideline Stroke. Jakarta: Perdossi; 2011.

6. Morgenstern LB, Hemphill JC III' ${ }^{\text {rd }}$, Anderson C, Becker K, Broderick JP, Connolly ES. Guidelines for the management of spontaneous intracerebral hemorrhage: A guideline. Am Heart Assoc 2010;41:2108-29.

7. Broderick J, Connolly S, Feldmann E, Hanley D, Kase C, Krieger D. Guidelines for the management of spontaneous intracerebral hemorrhage in adults: 2007 update: A guideline from the American heart Association/American Stroke Association Stroke Council, High Blood Pressure Research Council, and the Quality of Care and Outcomes in Research Interdisciplinary Working Group: The American Academy of Neurology affirms the value of this guideline as an educational tool for neurologists. Am Heart Assoc 2007;38:2001-23.

8. Sprigg N, Renton CJ, Dineen RA, Kwong Y, Bath PM. Tranexamic acid for spontaneous intracerebral hemorrhage: A randomized controlled pilot trial (ISRCTN50867461). J Stroke Cerebrovasc Dis 2014;23(6):1312-8.

9. Roos Y. Antifibrinolytic treatment in subarachnoid hemorrhage: A randomized placebo-controlled trial. STAR Study Group. Neurology 2000;54(1):77-82.

10. Tsementzis SA, Hitchcock ER, Meyer $\mathrm{CH}$. Benefits and risks of antifibrinolytic therapy in the management of ruptured intracranial aneurysms. A double-blind placebo-controlled study. Acta Neurochir (Wien) 1990;102(1-2):1-10.

11. Vermeulen M, Lindsay KW, Murray GD, Cheah F, Hijdra A, Muizelaar JP, et al. Antifibrinolytic treatment in subarachnoid hemorrhage. N Engl J Med 1984;311(7):432-7.

12. Wijdicks EF, Hasan D, Lindsay KW, Brouwers PJ, Hatfield R, Murray GD. Short-term tranexamic acid treatment in aneurysmal subarachnoid hemorrhage. Am Heart Assoc 1989;20:1674-9. 